\title{
DETECTION AND CHARACTERIZATION OF SUBSURFACE DEFECTS IN CONCRETE USING LOCK-IN AND STEP HEATING THERMOGRAPHY
}

\author{
D. Sharath ${ }^{\dagger *}$, M. Menaka, N. Raghu, B. Venkatraman \\ Health Safety and Environment Group \\ Indira Gandhi Centre for Atomic Research \\ Kalpakkam, 603102 INDIA \\ +'Presenting and Corresponding Author: sharath.universe@ gmail.com
}

\begin{abstract}
In this paper we discuss the application of Lock-in and Step heating techniques for defect detection in nuclear graded concrete structures. In case of Step Heating optimization of heating period is carried out by analyzing the Signal to Noise Ration and defect detectability. Also Thermal Signal Reconstruction is carried out for noise reduction and the results are compared. In Lockin Thermography depth probing is done by varying the frequency and the Signal to Noise Ratio and defect detectability limits are studied.
\end{abstract}

KEYWORDS: Concrete, Lock-in Thermography, Step Heating, Defect, Thermal Signal Reconstruction

\section{INTRODUCTION}

Concrete is one of the commonly used construction materials. In nuclear industries concretes are used as cost effective biological shield to prevent radiation hazard. The biological shield material and other concrete structures face extreme conditions like radiation and high temperature, which may induce damage in concrete structure. The induced damage may lead to defect creation which, if goes undetected, may lead to failure of the system. Non Destructive Evaluation (NDE) methods are suitable for such application since in NDE the material can be inspected without impairing its future usefulness. Since the concrete structure is situated in inaccessible area a non contact method is preferred. Infrared Thermography (IRT), being a non contact NDE method, is more suitable for in service inspection of concrete structures. In recent years IRT has gained more importance due to its ability to inspect noninvasively, fast inspection rates and provide a visual image which is easy to interpret [1]. Lock-in Thermography (LT) and Step Heating (SH) are two important techniques in active IRT which are widely used for material and defect characterization $[2,3]$. In LT, a periodically modulated optical wave is used to excite the material surface and the corresponding temperature response is recorded using an IR camera. Then mathematical tools such as Fourier Transform or Four Point Method are used to derive phase and amplitude images which are further used for quantitative analysis. In $\mathrm{SH}$ a continuous optical stimulus is used to heat the material surface and the temperature response during heating as well as cooling period is recorded. The temperature response is later analyzed for quantitative information. IRT has been widely used in civil engineering applications such as bridge inspection, detection of corrosion in reinforced bar in concretes, evaluation thermal insulation of buildings etc. In the case of concrete evaluation using thermography most of studies carried out on the detection of corrosion in reinforcement in concrete and resulting delamination using active thermography and damage detection in concrete. Defect detection in concrete is challenging compared to metals and composite due to its heterogeneous nature. The present study focuses on the initial lab scale study carried out on nuclear grade concrete for defect characterization using LT and SH. In LT frequency is varied for depth probing and Signal to Noise Ratio (SNR) is evaluated. In case of SH the heating period is optimized by evaluating the defect detectability and SNR. For SH Thermal Signal Reconstruction (TSR) is also carried out for reducing the noise and better defect detectability.

\section{MATERIAL AND EXPERIMENTAL SET UP}

\subsection{Material}


The material chosen was nuclear grade concrete. Polystyrene cubes of different sizes were used to simulate the defects. While casting the concrete the polystyrene cubes were placed at desired depths. For the present study defects of size $10 \mathrm{~cm} \times 10 \mathrm{~cm}, 5 \mathrm{~cm} \times 5 \mathrm{~cm}$ and $3 \mathrm{~cm} \times 3 \mathrm{~cm}$ at depth $1 \mathrm{~cm}, 2 \mathrm{~cm}$ and $3 \mathrm{~cm}$ respectively were created on concrete block of size $50 \mathrm{~cm}$ x $50 \mathrm{~cm}$ x $10 \mathrm{~cm}$.

\subsection{Experimental Setup}

A focal plane array based IR camera with thermal sensitivity of $25 \mathrm{mK}$ and maximum frame rate of $176 \mathrm{~Hz}$ was used for the experiment. The detector used was Indium Antimonide with spectral sensitivity in the range of $3 \mu \mathrm{m}$ to $5 \mu \mathrm{m}$. For both LT and SH, 4 halogen lamps of power $1000 \mathrm{~W}$ each were used. In LT A function generator was used to modulate the heat source and Altair LI software was used for data analysis. In SH the images were acquired with frame rate of $10 \mathrm{~Hz}$ during heating and for $10 \mathrm{~min}$ during cooling. The camera to object distance was $1.5 \mathrm{~m}$ and lamp to object distance was kept at $2 \mathrm{~m}$. Altair software was used for acquiring and analyzing the images.

\section{RESULTS AND DISCUSSION}

\subsection{Lock-in Thermography}

In LT, lower frequency was used since concrete has lower diffusivity. Frequencies ranging from $0.01 \mathrm{~Hz}$ to 0.0005 $\mathrm{Hz}$ were used to scan the depth. Figure 1 shows the phase images of concrete sample at frequencies $0.005 \mathrm{~Hz}$ and $0.001 \mathrm{~Hz}$
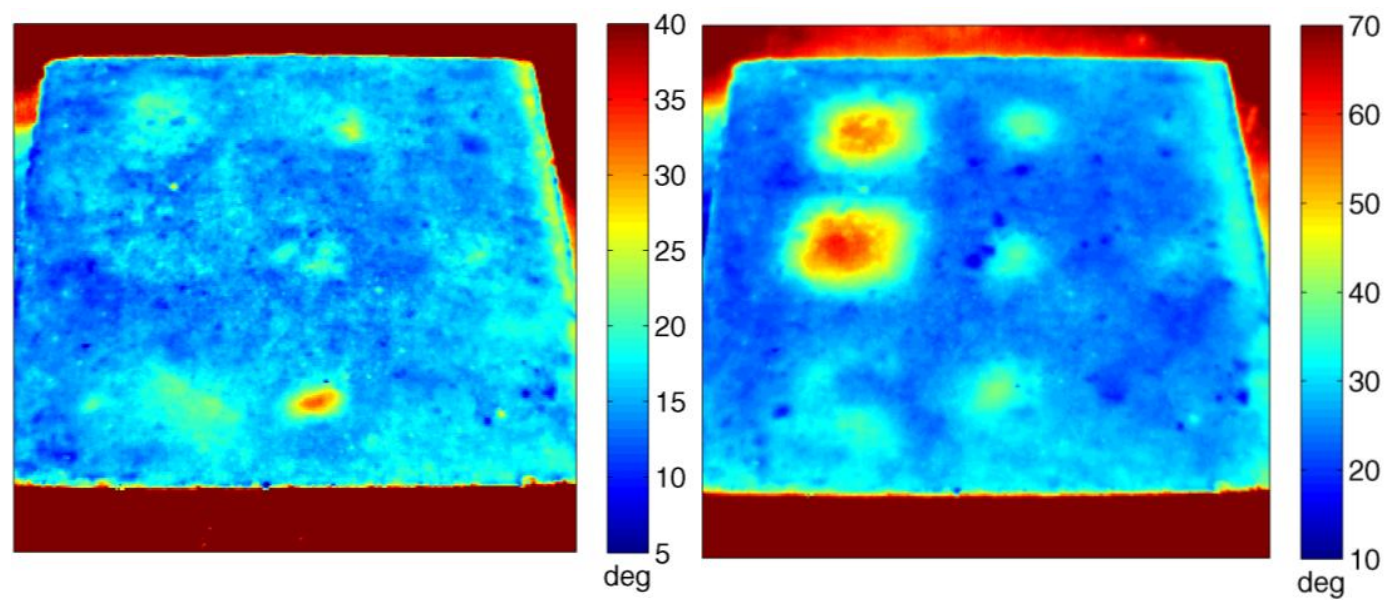

Fig. 1 Phase images of concrete sample at $\mathrm{f}=0.005 \mathrm{~Hz}$ and $0.001 \mathrm{~Hz}$.

\subsection{Step Heating}

In $\mathrm{SH}$ the heating period was varied from $10 \mathrm{sec}$ to $250 \mathrm{sec}$ and the analysis was carried out during the cooling period. Figure 2 shows thermal images of the sample at $100 \mathrm{sec}$ after heating for different heating times. TSR was carried out for cooling period and the corresponding $1^{\text {st }}$ and $2^{\text {nd }}$ derivative images were derived. The SNR analysis was also carried out and figure 3 shows the SNR variation as a function of time for defect of size $10 \mathrm{~cm} \times 10 \mathrm{~cm}$ at 1 cm depth. 


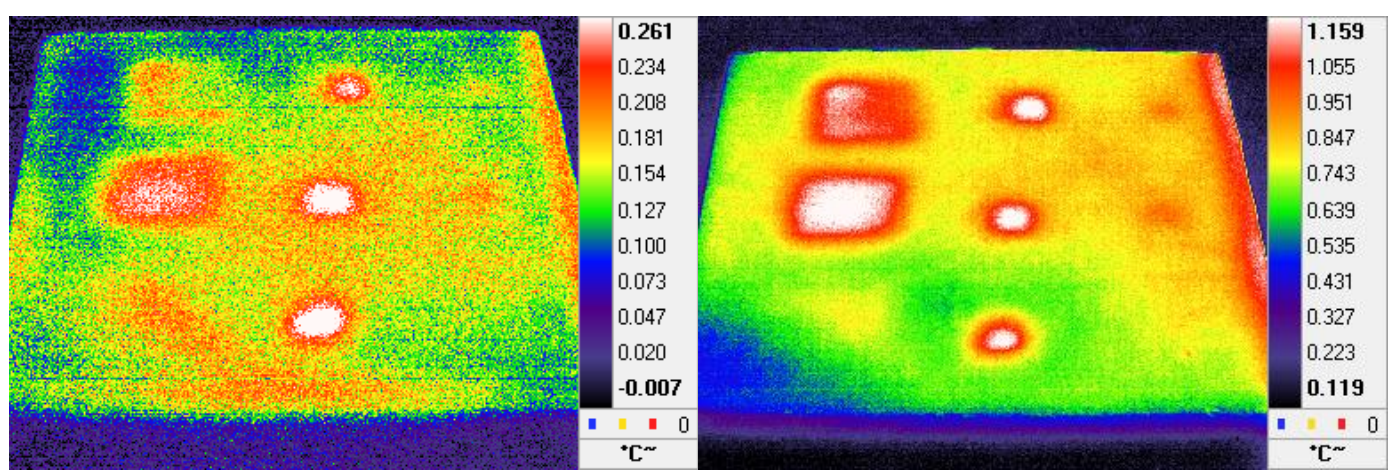

Fig. 2 Thermograms of the concrete sample at $\mathrm{t}=100 \mathrm{sec}$ for heating time of $25 \mathrm{sec}$ and $100 \mathrm{sec}$.

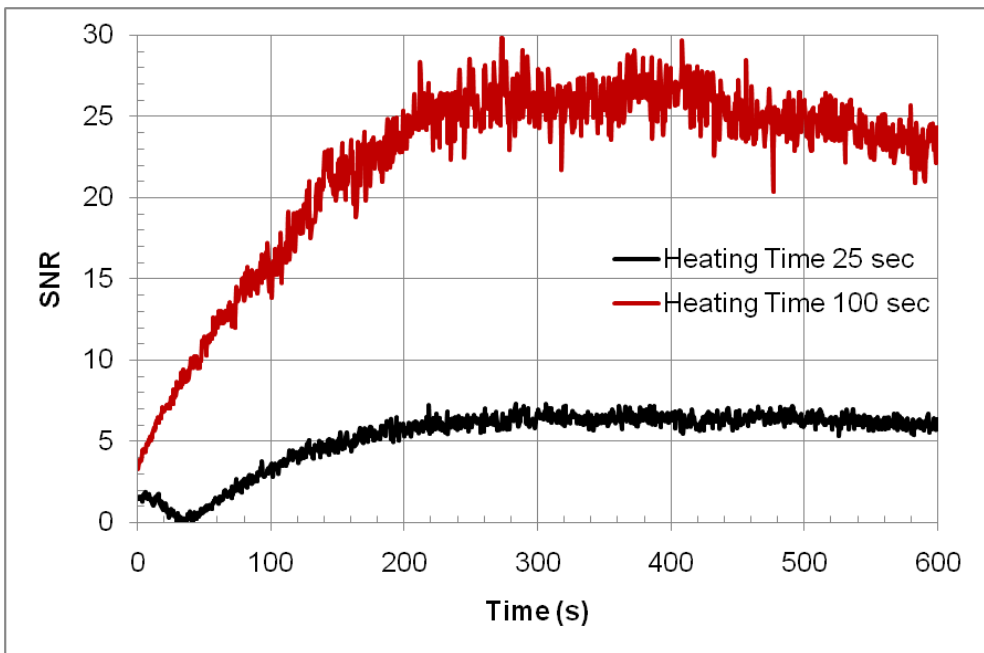

Fig. 3 SNR variation as a function of time for defect of size $10 \mathrm{~cm}$ x $10 \mathrm{~cm}$ at $1 \mathrm{~cm}$ depth.

\section{CONCLUSION}

Defect characterization in concrete was successfully carried out using LT and SH. Defect detectability and SNR in both techniques were analyzed and compared. Good SNR and defect detectability could be achieved by both the techniques. In SH the heating period is also optimized using SNR approach. It was observed that SH could detect finer defects than LT with the help of TSR.

\section{ACKNOWLEDGMENT}

We wish to thank Mr. Ashok and Mrs. R. Preetha, CEG, IGCAR for preparing the sample. We appreciate the assistance of Mr. Gnanamoorthy, Mr. S. Kumar and Mr. S. Aadithya during the experiment. We also thank Dr. A. K. Bhaduri, Director IGCAR for his consistence encouragement and support.

\section{REFERENCES}

[1] Xavier P.V.Maldague, Non-Destructive Evaluation of Materials by Infrared Thermography, Springer Verlag, 1993.

[2] D. Wu, W. Karpen, K. Haupt, H. G. Walther, G. Busse, Application of phase sensitive thermography for nondestructive evaluation, Journal De Physique, 04 1994: pp. C7 567 - C7 570.

[3] Osiander R, Spicer JW. Time-resolved infrared radiometry with step heating. A review. Revue Générale de Thermique. 37 (8) 1998: pp. 680-92. 